\title{
Isolated Medullary Hemorrhage: Clinical Features in Eleven Consecutive Patients
}

\author{
Sun-Uk Lee, ${ }^{\mathrm{a}}$ Hyo-Jung Kim, ${ }^{\mathrm{b}}$ Bong-Su Kang, ${ }^{\mathrm{c}}$ Ji-Soo Kim ${ }^{\mathrm{b}}$ \\ aDepartment of Neurology, Ajou University School of Medicine, Ajou University Hospital, Suwon, Korea \\ bDepartment of Neurology, Seoul National University College of Medicine, Seoul National University Bundang Hospital, Seongnam, Korea \\ 'Department of Neurology, Yangpyeong Hospital, Yangpyeong-gun, Gyeonggi-do, Korea
}

\section{Dear Sir:}

Most brainstem hemorrhages occurring in the pons and midbrain, and hemorrhages restricted to the medulla oblongata have received little attention to date. Herein, we describe the clinical characteristics and prognosis of 11 patients (four men, age range of 11 patients: $20-65$ years, mean age $=44$ ) with medullary hemorrhage recruited consecutively from Seoul National University Bundang Hospital from July 2004-January 2016 (Figure 1).

The most frequent symptoms in these patients included vertigo $(n=10)$, headache $(n=6)$, diplopia $(n=3)$, and limb weakness $(n=1)$. Table 1 shows the clinical features and prognosis of patients. More than half of patients $(6 / 11,55 \%)$ experienced minor transient or persistent neurologic symptoms, including vertigo $(n=3)$, sensory changes in the face $(n=2)$ or extremities $(n=2)$, dysarthria $(n=1)$, tinnitus $(n=1)$, and dysphagia $(n=1)$, within one month of presentation. In contrast, five patients $(5 / 11,46 \%)$ required advanced airway management in the intensive care unit. Hematoma expansion was observed in four patients during follow-up imaging $(4 / 9,44 \%)$. Patients usually had minor functional deficits three months after presentation (modified Rankin Scale $\leq 2$ and/or Bathel Index 90; $n=8$ ).

All patients showed spontaneous nystagmus without fixation ( $n=11$; upbeat in eight, downbeat in one, and horizontal in two), which accompanied other neuro-otological findings (Table 2), including central positional nystagmus $(7 / 9,78 \%)$, gaze-evoked nystagmus $(6 / 11,55 \%)$, ocular lateropulsion $(4 / 11,36 \%)$, skew deviation $(5 / 11,45 \%)$, or abnormal head-impulse tests $(3 / 11$, $27 \%$ ). The etiologies of the medullary hemorrhages were mostly cavernous malformation $(n=9)$, hemorrhagic transformation following lateral medullary infarction $(n=1$, patient 5$)$, or undetermined $(n=1$, patient 1$)$.

In our patients, the presenting symptoms were mostly vertigo and headache. Furthermore, over half of the patients experienced prior minor neurologic symptoms, which is uncommon in pontine or midbrain hemorrhage. ${ }^{1-3}$ In contrast, most patients with pontine hemorrhage present with mental changes (47\%) or hemiparesis $(41 \%))^{2}$ Likewise, patients with midbrain hemorrhage frequently show mental changes (53\%), and limb weakness (49\%). ${ }^{3}$ Thus, we assume that the characteristics of hemorrhage secondary to cavernous malformation are different from those due to hypertensive hemorrhages. Intermingled vascular spaces or sinusoids would be affected less by arterial pressure than regions irrigated by small arterioles, which are vulnerable to hypertension. ${ }^{4}$ Neurological impairments may worsen due to repeated seepage or oozing, or due to the toxic effects of hemosiderin deposits. Approximately half of our patients eventually showed a mental change that prompted mechanical ventilation. Therefore, close observation is essential in such patients.

Here, the cause of medullary hemorrhage was mostly cavernous malformation, which refers to abnormally enlarged vascular cavities without intervening brain parenchyma. Approximately $5 \%$ of cavernous malformations involving the brainstem reside in the medulla oblongata. ${ }^{5}$ Unlike those in the supratentorial area, the cavernous malformations involving the brainstem become symptomatic easily, and neurological progression can occur because of even a small amount of bleeding. Although about half of our patients experienced severe neurological deteriora- 


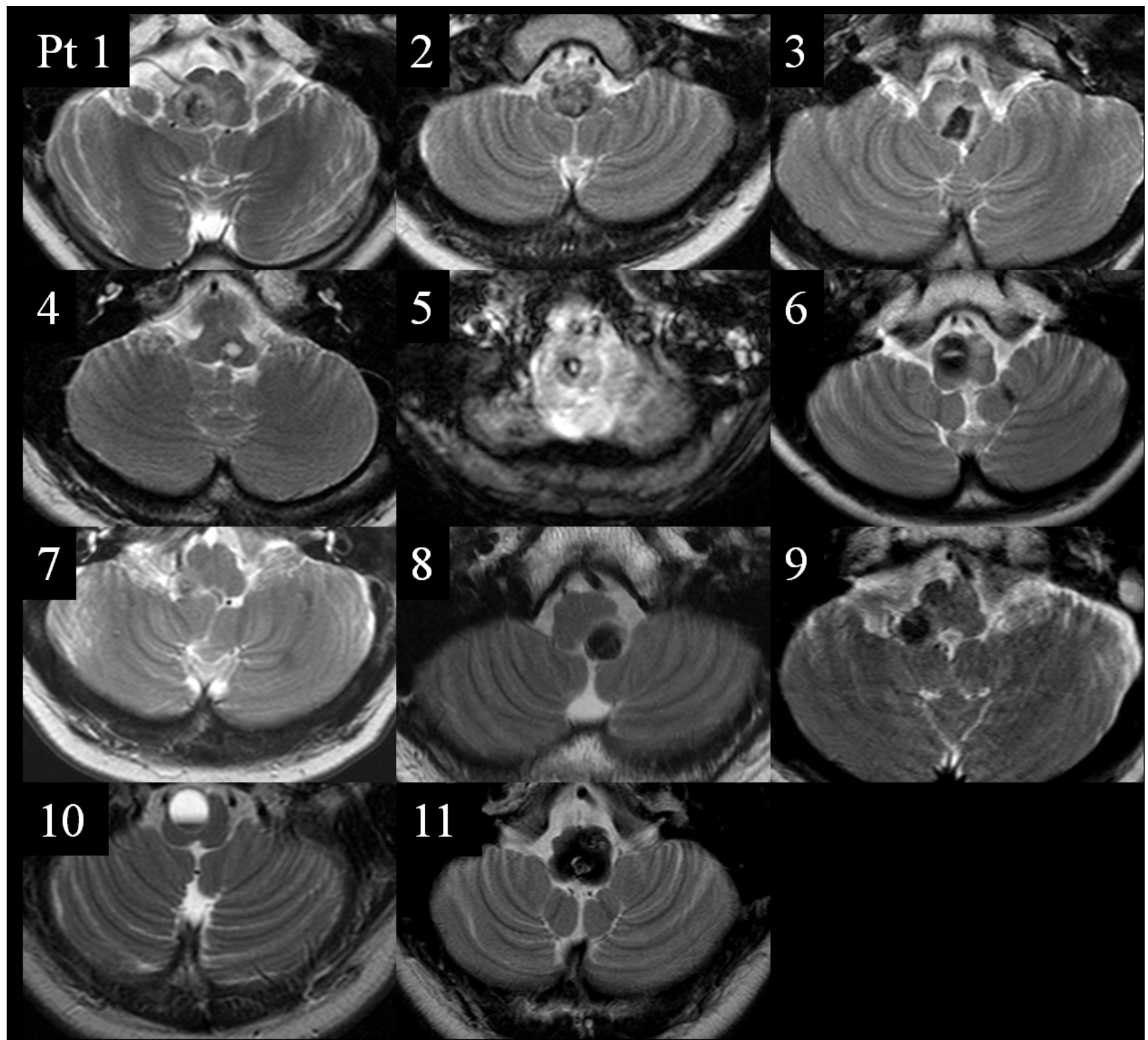

Figure 1. Brain magnetic resonance images (MRIs) of patients with medullary hemorrhage. The lesions are unilateral in eight $(1,4-10)$, and bilateral in the remaining three patients $(2,3$, and 11$)$.

tion that required mechanical ventilation, the overall outcome after three months was relatively favorable compared to pontine hemorrhage, in which patients mostly end up in a vegetative state or die, and independent living is rarely possible (18\%). ${ }^{2}$

All patients presented with typical neurological findings, mostly resulting from the involvement of the neural structures in the medulla oblongata, including the medial lemniscus, spinothalamic tract, tract of the trigeminal nerve, inferior cerebellar peduncle, nucleus ambiguous, and hypoglossal nucleus. ${ }^{6,7}$ We propose that the intercalatus nucleus and the nucleus of Roller, or the caudal cell groups of the paramedian tract may be the neural substrates for the upbeat or downbeat nystagmus ob- served here. In contrast, the dissociated torsional-upbeat nystagmus observed in two patients might be explained by unilateral or bilateral damage to the vestibulo-ocular reflex pathway ascending in the medial longitudinal fasciculus. ${ }^{8}$ The direction-changing gaze-evoked nystagmus indicates damage to the vestibular nucleus or nucleus prepositus hypoglossi. ${ }^{9}$ Disruption of the nodulouvular projections onto the vestibular nuclei may cause apogeotropic or geotropic positional nystagmus. ${ }^{10}$ Ocular lateropulsion has been ascribed to damage of the olivocerebellar fibers, before or after decussation in the medulla, projecting to the cerebellar Purkinje cells, which in turn project to the paramedian pontine reticular formation. ${ }^{11}$ 
Table 1. Clinical characteristics of the patients

\begin{tabular}{|c|c|c|c|c|c|c|c|}
\hline \multirow[b]{2}{*}{ Pt } & \multicolumn{2}{|r|}{ Clinical presentation } & \multirow{2}{*}{$\begin{array}{l}\text { Neurologic deteriora- } \\
\text { tion (day) that necessi- } \\
\text { tated advanced airway } \\
\text { management* }\end{array}$} & \multirow{2}{*}{$\begin{array}{c}\text { Hematoma } \\
\text { expansion }\end{array}$} & \multicolumn{2}{|c|}{ 3-month prognosis } & \multirow[b]{2}{*}{ Etiology } \\
\hline & Chief complaint & Other findings (initial NIHSS score) & & & $\mathrm{mRS}$ & $\mathrm{BI}$ & \\
\hline 1 & Vertigo & $\begin{array}{l}\text { Dysphagia, dysarthria, hiccup, hoarseness, facial/limb } \\
\text { weakness and sensory change (4) }\end{array}$ & $+(2)$ & + & 2 & 85 & Unknown \\
\hline 2 & Vertigo, diplopia & Facial/limb sensory change (2) & - & - & 1 & 100 & $\mathrm{CM}$ \\
\hline 3 & Vertigo, headache & $\begin{array}{l}\text { Dysphagia, dysarthria, ataxia, INO, tongue deviation, } \\
\text { soft palate palsy (4) }\end{array}$ & $+(2)$ & + & 1 & 89 & $\mathrm{CM}$ \\
\hline 4 & Vertigo, headache & $\begin{array}{l}\text { Dysphagia, hoarseness, limb weakness, facial/limb } \\
\text { sensory change (3) }\end{array}$ & - & - & 1 & 100 & $\mathrm{CM}$ \\
\hline 5 & Limb weakness & Dysphagia, dysarthria (4) & $+(7)$ & No F/U & 3 & 79 & $\begin{array}{l}\text { Hemorrhagic } \\
\text { transformation }\end{array}$ \\
\hline 6 & Vertigo, headache & Dysphagia, dysarthria, ataxia, Horner's syndrome (2) & $+(3)$ & + & 4 & 6 & $\mathrm{CM}$ \\
\hline 7 & $\begin{array}{l}\text { Vertigo, headache, } \\
\text { diplopia }\end{array}$ & Ataxia, Horner's syndrome, tongue deviation (1) & - & - & 0 & 100 & $\mathrm{CM}$ \\
\hline 8 & Vertigo, diplopia & Dysarthria, facial/truncal sensory change (3) & - & - & 1 & 100 & $\mathrm{CM}$ \\
\hline 9 & Vertigo, headache & Ataxia, Horner's syndrome (2) & - & - & 1 & 90 & $\mathrm{CM}$ \\
\hline 10 & Vertigo & $\begin{array}{l}\text { Dysphagia, dysarthria, ataxia, facial/truncal sensory } \\
\text { change, tongue deviation (5) }\end{array}$ & $+(10)$ & + & 6 & 0 & $\mathrm{CM}$ \\
\hline 11 & Vertigo & Ataxia, soft palate palsy (2) & - & No F/U & 1 & 90 & $\mathrm{CM}$ \\
\hline
\end{tabular}

Pt, patient; NIHSS, National Institutes of Health stroke scale; mRS, modified Rankin scale; BI, Bathel Index; CM, cavernous malformation; INO, internuclear ophthalmoplegia; F/U, follow-up.

*Indicates the interval (days) from presentation.

Table 2. Neuro-otological findings in patients

\begin{tabular}{|c|c|c|c|c|c|c|c|c|c|}
\hline Pt & Age/Sex & Lesion & Spontaneous nystagmus & $\begin{array}{c}\text { Ocular } \\
\text { lateropulsion }\end{array}$ & hGEN & HIT & HSN & $\begin{array}{l}\text { Positional } \\
\text { nystagmus }\end{array}$ & Caloric paresis (\%) \\
\hline 1 & $\mathrm{~F} / 65$ & $\mathrm{R}$ & $U, R$ & - & - & - & - & Apogeotropic & Normal \\
\hline 2 & $\mathrm{~F} / 20$ & Bilateral & U (OU) & - & + & - & $L, U$ & Apogeotropic & Normal \\
\hline 3 & $M / 22$ & Bilateral & $\mathrm{R}$ & $\mathrm{R}$ & + & $\mathrm{R}$ & - & Apogeotropic & Not performed \\
\hline 4 & $\mathrm{~F} / 42$ & L & D & - & - & - & - & - & Normal \\
\hline 5 & $\mathrm{M} / 72$ & $\mathrm{R}$ & $\mathrm{L}$ & - & - & - & - & Apogeotropic & Not performed \\
\hline 6 & $\mathrm{~F} / 35$ & $\mathrm{R}$ & $\begin{array}{l}\text { Dissociated torsional-upbeat, L } \\
\text { (OD: upbeat dominant; OS: } \\
\text { CCW dominant) }\end{array}$ & $\mathrm{R}$ & + & - & - & Not evaluated & Not performed \\
\hline $7^{*}$ & $\mathrm{~F} / 52$ & $\mathrm{R}$ & U, CCW & - & + & $\mathrm{R}$ & - & Apogeotropic & No response, both \\
\hline 8 & $M / 33$ & $\mathrm{~L}$ & $U$ & - & - & - & $\mathrm{L}$ & Geotropic & Normal \\
\hline 9 & $M / 63$ & $\mathrm{R}$ & Bowtie & $\mathrm{R}$ & + & - & - & Apogeotropic & Not performed \\
\hline $10^{*}$ & $\mathrm{~F} / 52$ & $\mathrm{R}$ & $U, L$ & $\mathrm{R}$ & + & L & Not evaluated & Not evaluated & Not performed \\
\hline 11 & $\mathrm{~F} / 26$ & Bilateral & U & - & - & - & - & - & Not performed \\
\hline
\end{tabular}

Pt, patient; hGEN, horizontal gaze-evoked nystagmus; HIT, head-impulse test; HSN, head-shaking nystagmus; F, female; R, right; U, up; OU, both eyes; L, left; $M$, male; $D$, downbeat; $O D$, right eye; $O S$, left eye; $C C W$, counter-clockwise (upper poles of the eyes beating to the left shoulder).

*Patients with only bedside neuro-otologic examination.

Neuro-otologic evaluation may prove valuable for detecting medullary hemorrhage. Given the rare incidence of spontaneous hemorrhages in the medulla, underlying vascular malformations should be considered.

\section{Ethical standard}

This study followed the tenets of the Declaration of Helsinki and was performed according to the guidelines of Institutional
Review Board of Seoul National University Bundang Hospital (B1109/135-106).

\section{References}

1. Masiyama S, Niizuma H, Suzuki J. Pontine haemorrhage: a clinical analysis of 26 cases. J Neurol Neurosurg Psychiatry 1985;48: 658-662.

2. Nakajima K. Clinicopathological study of pontine hemorrhage. 
Stroke 1983;14:485-493.

3. Link MJ, Bartleson JD, Forbes G, Meyer FB. Spontaneous midbrain hemorrhage: report of seven new cases. Surg Neurol 1993; 39:58-65.

4. Little JR, Awad IA, Jones SC, Ebrahim ZY. Vascular pressures and cortical blood flow in cavernous angioma of the brain. J Neurosurg 1990;73:555-559.

5. Fritschi JA, Reulen HJ, Spetzler RF, Zabramski JM. Cavernous malformations of the brain stem. A review of 139 cases. Acta Neurochir (Wien) 1994;130:35-46.

6. Kim JS. Pure lateral medullary infarction: clinical-radiological correlation of 130 acute, consecutive patients. Brain 2003;126: 1864-1872.

7. Kim JS, Han YS. Medial medullary infarction: Clinical, imaging, and outcome study in 86 consecutive patients. Stroke 2009;40: 3221-3225.

8. Lee SU, Park SH, Jeong SH, Kim HJ, Kim JS. Evolution of torsional-upbeat into hemi-seesaw nystagmus in medial medullary infarction. Clin Neurol Neurosurg 2014;118:80-82.

9. Lee SU, Park SH, Park JJ, et al. Dorsal medullary infarction: Distinct syndrome of isolated central vestibulopathy. Stroke 2015;
46:3081-3087.

10. Choi JY, Kim JH, Kim HJ, Glasauer S, Kim JS. Central paroxysmal positional nystagmus: Characteristics and possible mechanisms. Neurology 2015;84:2238-2246.

11. Leigh RJ, Zee DS. The neurology of eye movements, 5th ed. New York: Oxford University Press, 2015.

Correspondence: Ji-Soo Kim

Department of Neurology, Seoul National University College of Medicine, Seoul National University Bundang Hospital, 82 Gumi-ro, 173beon-gil, Bundang-gu, Seongnam 13620, Korea

Tel: +82-31-787-7463; Fax: +82-31-719-6828

Email: jisookim@snu.ac.kr

Received: December 11, 2016

Revised: December 13, 2016

Accepted: December 13, 2016

This study was supported by a grant from the Korea Healthcare Technology R\&D Project, Ministry of Health and Welfare, Republic of Korea (HI10C2020).

The authors have no financial conflicts of interest 